\title{
Comparison of Three Experimental Models for Rat Osteoarthritis Induction
}

\section{Henrique Ribeiro Rodrigues-Neto', Edilson Ferreira Andrade-Junior1, Denilson Jose Silva Feitosa-Junior ${ }^{2}$, André Lopes Valente' ${ }^{2}$, Thiago Cesar Xavier ${ }^{2}$, Bianca Caroline do Nascimento Alho' ${ }^{2}$, Renan Kleber Costa Teixeira ${ }^{2}$, Fabio Vidal Moriya ${ }^{1,2}$, Rui Sérgio Monteiro de Barros ${ }^{1,2 *}$}

${ }^{1}$ Department of Orthopaedics and Traumatology, Porto Dias Hospital, Belém, Brazil

${ }^{2}$ Experimental Surgery Laboratory, Pará State University, Belém, Brazil

Email: henriqueneto85@gmail.com, edilsonfajr@gmail.com, denilsonfmed@gmail.com, andrevalentelop@gmail.com, thiagocesarxavier@hotmail.com, biank_caroline@hotmail.com, renankleberc@hotmail.com,drfabiomoriya@hotmail.com,

*ruibarros@me.com

How to cite this paper: Rodrigues-Neto, H.R., Andrade-Junior, E.F., Feitosa-Junior, D.J.S., Valente, A.L., Xavier, T.C., do Nascimento Alho, B.C., Teixeira, R.K.C., Moriya, F.V. and de Barros, R.S.M. (2016) Comparison of Three Experimental Models for Rat Osteoarthritis Induction. Journal of Biosciences and Medicines, 4, 62-69.

http://dx.doi.org/10.4236/jbm.2016.412010

Received: October 14, 2016

Accepted: November 28, 2016

Published: December 1, 2016

Copyright $\odot 2016$ by authors and Scientific Research Publishing Inc. This work is licensed under the Creative Commons Attribution International License (CC BY 4.0).

http://creativecommons.org/licenses/by/4.0/

\begin{abstract}
Background: Osteoarthritis is a slowly progressive and debilitating disease with high prevalence in adult population. Knee is one of the joints most affected by this disorder. There are several models for animals' osteoarthritis induction, however it is not identified any paper that compares these techniques. The present study was aimed to define the most appropriate model for rats osteoarthritis induction. Material and Methods: 40 Wistar rats were distributed into 4 groups of 10 animals each: normality group (NG); meniscectomy group (MG); quinolone group (QG) and iodoacetate group (IG). Radiographic images of the rat's knees were analyzed as well as the amount of chondrocytes in the epiphyseal and articular cartilage. Results: In the radiographic analysis, there was a low correlation between the raters. Regarding the amount of chondrocytes in the epiphyseal cartilage, it was noticed that the IG and QG groups had fewer chondrocytes than NG, in contrast to MG that reported similar results to normality ( $p>0.05)$. There was no significant difference between IG and QG groups $(p>0.05)$. Regarding the amount of chondrocytes in articular cartilage, it was noticed that the IG group showed fewer chondrocytes than NG $(\mathrm{p}<0.01)$, in contrast to the QG and MG groups that showed similar results to normality ( $p>0.05$ ). There was no significant difference between QG and MG groups $(p>0.05)$. Conclusion: Intraarticular injection of iodoacetate in rats is the model with greatest effect on reduction of chondrocytes amount.
\end{abstract}

\section{Keywords}

Osteoarthritis, Knee Joint, Experimental Arthritis, Animal Disease Models, Rats 


\section{Introduction}

Osteoarthritis is a slowly progressive and debilitating disease with high prevalence in adult population [1] [2]. Knee is one of the joints most affected by this disorder and it generates a great function loss and decreases quality of life of those patients [3] [4]. It is estimated that the prevalence of this disease is $60 \%$ in men and $70 \%$ in women over 65 years [1] [4].

Knee osteoarthritis is classified as either primary (idiopathic) or secondary. Secondary osteoarthritis is often the result of injury (trauma) or repetitive motion. It can also be a result of congenital conditions and underlying diseases, including systemic metabolic diseases, endocrine diseases, bone dysplasia, and calcium crystal deposition diseases [5] [6].

Osteochondral defects often evolve to joint degeneration, characterized by pain, rigidity and loss of mobility [7]. The articular cartilage has a limited potential of healing because it is not vascularized, making their treatment become a challenge [8]. When the chondrocytes are injured, they do not form hematomas, do not produce fibrin nor form clot, serving only as support for the repair tissue and limiting the inflammatory response [9] [10].

There is not any appropriate treatment for this disease, being treated with analgesics and anti-inflammatories [11] [12]. New researches are necessary to develop medications that combat this disease in its various phases. Many experimental studies have demonstrated some promising results, but they differ several times in the chosen method to induce osteoarthritis [13]-[18].

The main models used to induce osteoarthritis are: 1) Meniscectomy [13] [14], which the lesion generates articular trauma, facilitating the process of arthritis; 2) Administration of quinolone [15] [16], mainly ciprofloxacin which has articular toxicity changing the chondrocytes and stimulating their apoptosis; and 3) Intraarticular injection of iodoacetate [17] [18] that generates an intense inflammatory infiltrate, culminating in the osteoarthritis. The three methods are more likely to mimic secondary osteoarthritis.

Although these models induce the osteoarthritis in all the animals they are used, in the literature review, it was not identified any paper that compared these techniques. Therefore, the present study was aimed to compare different experimental models in rats osteoarthritis induction.

\section{Material and Methods}

\subsection{Ethical Considerations}

This research strongly followed the rules from the Brazilian Law for Animal Care (Law 11.794/08), based on the guidelines from National Institutes of Health (NIH), and the Ethics Code for Animal Experimentation from the Council for International Organizations of Medical Sciences. The Animal Ethics Committee from Pará State University approved the plan of this study (Protocol 35/14).

\subsection{Experimental Design}

40 male Wistar rats were used (Rattus norvegicus) aging 4 months and weighting be- 
tween 200 - 250 grams from the Animal House of the Experimental Surgery Laboratory. They were maintained in appropriate cages with no restriction of food or water.

The animals were randomly distributed into four groups, each with 10 rats: 1) Normality Group (NG); 2) Meniscectomy Group (MG); 3) Iodoacetate Group (IG) and 4) Quinolone Group (QG).

\subsection{Osteoarthritis Induction}

The method to induce osteoarthritis varied according to the group. For the MG and IG, the rats were anesthetized by ketamine $(70 \mathrm{mg} / \mathrm{kg})$ and xylazine $(10 \mathrm{mg} / \mathrm{kg})$ and the trichotomy and antisepsis of the left posterior limb were performed. In the MG, an incision was made medial and parallel to the patella; this bone was displaced medially and the medial collateral ligament was sectioned with the knee flexed [13] [14]. In the end, the suture was held by plans with 6-0 nylon.

Already in the IG, the animals get a single dose of $2 \mathrm{mg}$ of sodium iodoacetate in 25 $\mu \mathrm{L}$ directly on the knee joint with the paw flexed to $90^{\circ}$ [17]. Finally, the rats of QG received oral administration of ciprofloxacin $(20 \mathrm{mg} / \mathrm{kg})$ once a day during 15 days, always in the same time [16].

\subsection{Radiographic and Histopathological Analysis}

After 28 days from the surgery and the beginning of ciprofloxacin administration the rats were euthanized by anesthetics overdose. The left posterior limb of all the animals was disarticulated from the hip joint. Then, the femur was separated from the soft tissue and the tibia was disarticulated from the fibula.

For the radiographic evaluation, the limbs were positioned in extension of $180^{\circ}$ and anteroposterior radiographs were taken. It was used mammography films with a radiographic technic of $22 \mathrm{kV}, 20 \mathrm{mAs}$, time of $0.71 \mathrm{~s}, 1.6 \times$ magnification and focal distance of $20 \mathrm{~cm}$. Two blind researchers evaluated the X-ray images and graduated them in: 0-no lesion; 1-minimal lesion; 2-moderate lesion; 3-intense lesion.

For the histopathological analysis, the tissue was fixed in formaldehyde, demineralized in nitric acid and followed for routine processing being stained by hematoxylineosin. The slides were analyzed by the quantity of chondrocytes in the epiphyseal and articular cartilage in five high magnifications fields $(40 \times)$.

\subsection{Data Analysis}

The normal distribution of data was confirmed by Kolmogorov-Smirnov test. The results of the radiographic analysis were correlated by interclass test. Already the histopathological results were analyzed by ANOVA and Tukey test. All the tests considered $\mathrm{p}$ value $<0.05$.

\section{Results}

In the radiographic analysis was a low correlation between the raters (correlation factor of 0.12) being opted for the exclusion of this study variable due to the high chance of bias. 


\subsection{Epiphyseal Cartilage Chondrocytes}

Regarding the epiphyseal cartilage chondrocytes average counting (Table 1; Figure 1), IG and QG had less chondrocytes counting than the NG and MG $(\mathrm{p}<0.01)$. Oh the other hand, MG showed similar average with the normality group $(p>0.05)$, both with high chondrocytes amount. There was no significant statistical difference between IG and QG ( $p>0.05)$. MG had higher standard deviation than others group.

\subsection{Articular Cartilage Chondrocytes}

About the articular cartilage chondrocytes (Table 2; Figure 2), IG showed less average of chondrocytes with $60.30 \pm 7.85$, which was statistically different than NG, QG and MG ( $\mathrm{p}<0.01)$. In contrast, QG $(86.60 \pm 13.14)$ and MG $(83.60 \pm 14.45)$ showed similar results with the normality, without statistical difference $(p>0.05)$. There was no significant statistical difference between the groups QG and MG ( $p>0.05)$.

\section{Discussion}

The choice of an animal disease model should take in count many factors, as age, sex, weight and others. If these factors do not be controlled biases will occur in the research models [19] [20]. Regarding the osteoarthritis induction, there are three main models

Table 1. Epiphyseal cartilage chondrocytes average according to the groups.

\begin{tabular}{ccc}
\hline & \multicolumn{2}{c}{ Epiphyseal cartilage chondrocytes } \\
\cline { 2 - 3 } Group & Average & Standard deviation $( \pm)$ \\
\hline Iodoacetate (IG) & $69.70^{\star}$ & 7.68 \\
Quinolone (QG) & $64.20^{\star}$ & 4.27 \\
Meniscectomy (MG) & 82.40 & 10.81 \\
Normality (NG) & 90.10 & 4.85 \\
\hline
\end{tabular}

${ }^{*} \mathrm{p}<0.01$ (ANOVA) when compared with the Normality Group.

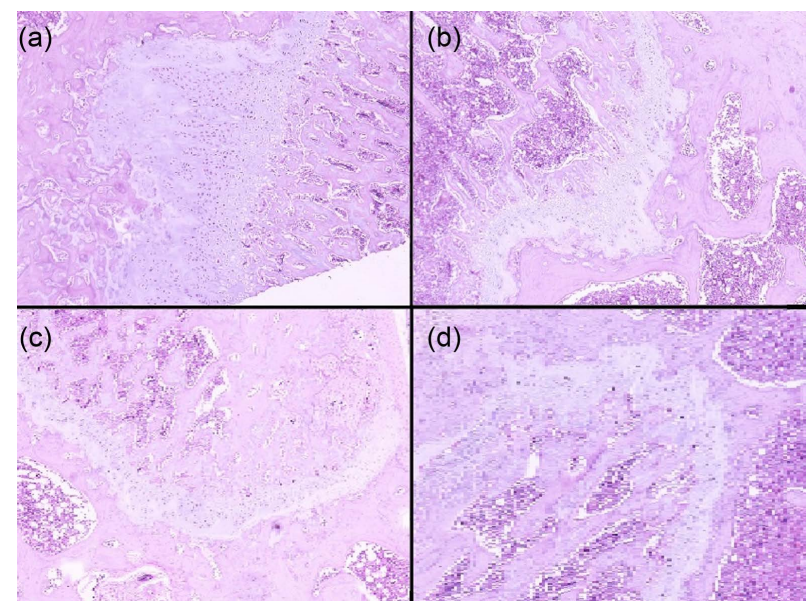

Figure 1. Epiphyseal cartilages according to the groups. Hematoxylin and eosin staining, 25×. (a) Iodoacetate; (b) Quinolone; (c) Meniscectomy; (d) Normality. 
Table 2. Articular cartilage chondrocytes average according to the groups.

\begin{tabular}{ccc}
\hline \multirow{2}{*}{ Group } & \multicolumn{2}{c}{ Articular cartilage chondrocytes } \\
\cline { 2 - 3 } & Average & Standard deviation $( \pm)$ \\
\hline Iodoacetate (IG) & $60.30^{*}$ & 7.85 \\
Quinolone (QG) & 86.60 & 13.14 \\
Meniscectomy (MG) & 83.60 & 14.45 \\
Normality (NG) & 92.30 & 9.04 \\
\hline
\end{tabular}

${ }^{*} \mathrm{p}<0.01$ (ANOVA) when compared with the Normality Group.

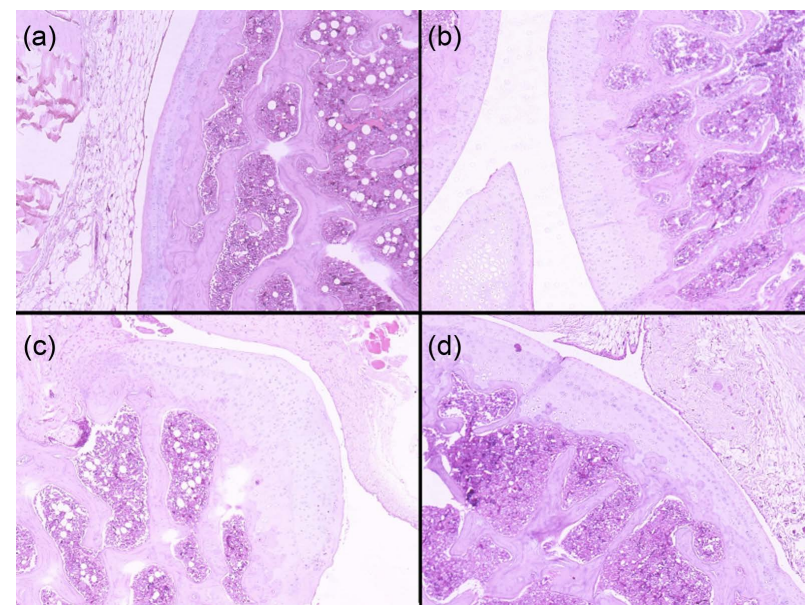

Figure 2. Articular cartilages according to the groups. Hematoxylin and eosin staining, 25×. (a) Iodoacetate; (b) Quinolone; (c) Meniscectomy; (d) Normality.

used in the literature, reducing the comparability of the results and making the achievement of meta-analyze difficult [13]-[20].

The chondrocytes are cells that main function is the synthesis of the joint extracellular matrix, thus decrease of those cells by trauma of inflammation may cause diseases such as osteoarthritis. That is why the count of chondrocytes was used in this research to compare the lesions of different methods; the same was done in other studies [10] [11] [21].

Intraarticular iodoacetate injection appeared to be the most appropriated way to induce osteoarthritis due to the IG animals showed less chondrocytes than others did. In this study, the meniscectomy was the worst method since the number of chondrocytes was almost the same of the normality group. It is believed that it occurred because the surgery did have more variables that can influence the outcome. The fact that this group had the highest standard deviation in the count of both articular and epiphyseal cartilage reinforces this idea.

The use of ciprofloxacin (QG) showed similar results in the epiphyseal cartilage and slightly lower in the articular cartilage when compared to the IG. However, the QG group had the inconvenience of a long time of oral administration diverging from the iodoacetate group, which needs just one day of injection, reducing the research time 
and the animal stress.

Even the intraarticular injection of iodoacetate was considered the most apropriate model to induce osteoarthritis, the other methods should be used because they can simulate different etiology of injuries such as knee osteoarthritis by trauma (meniscectomy) and drug-induced (quinolone) with advantage if specific treatment for these causes is being researched [19] [20]. Besides, there is no standard dosage for intraarticular iodoacetate injection, which could accurate the comparison between three models, further studies about its dosage-dependent relation would be useful.

One of the limitations of this study was the evaluation only by the count of chondrocytes; more parameters such as other histopathological criteria and the macroscopy have not been used, we suggest that they should be used in other researches [13]-[18]. Moreover, a long time observation might change the outcomes, although the period used is the most common in the literature. In addition, in future researches different doses of ciprofloxacin or other quinolones may be used [15] [20] [22].

\section{Conclusion}

Based on reduction of chondrocytes counting, the most appropriate model to induce osteoarthritis in rats is the intraarticular injection of iodoacetate.

\section{Acknowledgements}

All the authors thank Daniel Haber Feijó, Eduardo Henrique Herbster Gouveia and Luan Teles Ferreira de Carvalho, trainees from the Experimental Surgery Laboratory from Pará State University for helping in this study.

\section{References}

[1] Litwic, A., Edwards, M.H., Dennison, E.M. and Cooper, C. (2013) Epidemiology and Burden of Osteoarthritis. British Medical Bulletin, 105, 185-199. https://doi.org/10.1093/bmb/lds038

[2] Neogi, T. and Zhang, Y. (2013) Epidemiology of Osteoarthritis. Rheumatic Diseases Clinics of North America, 39, 1-19. https://doi.org/10.1016/j.rdc.2012.10.004

[3] Plotnikoff, R., Karunamuni, N., Lytvyak, E., Penfold, C., Schopflocher, D., Imayama, I., Johnson, S.T. and Raine, K. (2015) Osteoarthritis Prevalence and Modifiable Factors: A Population Study. BMC Public Health, 15, 1195. https://doi.org/10.1186/s12889-015-2529-0

[4] Cunha-Miranda, L., Faustino, A., Alves, C., Vicente, V. and Barbosa, S. (2015) Assessing the Magnitude of Osteoarthritis Disadvantage on People's Lives: The MOVES Study. Revista Brasileira de Reumatologia, 55, 22-30. https://doi.org/10.1016/j.rbr.2014.07.009

[5] Michael, J.W., Schlüter-Brust, K.U. and Eysel, P. (2010) The Epidemiology, Etiology, Diagnosis, and Treatment of Osteoarthritis of the Knee. Deutsches Ärzteblatt international, 107, 152-162. https://doi.org/10.3238/arztebl.2010.0152

[6] Samson, D.J., Grant, M.D., Ratko, T.A., Bonnell, C.J., Ziegler, K.M. and Aronson, N. (2007) Treatment of Primary and Secondary Osteoarthritis of the Knee. Evidence Reports/Technology Assessments, 157, 1-157.

[7] Roddy, E., Thomas, M.J., Marshall, M., Rathod, T., Myers, H., Menz, H.B., Thomas, E. and Peat, G. (2015) The Population Prevalence of Symptomatic Radiographic Foot Osteoarthri- 
tis in Community-Dwelling Older Adults: Cross-Sectional Findings from the Clinical Assessment Study of the Foot. Annals of the Rheumatic Diseases, 74, 156-163.

https://doi.org/10.1136/annrheumdis-2013-203804

[8] Rezende, M.U., Campos, G.C. and Pailo, A. (2013) Current Concepts in Osteoarthritis. Acta Ortopedica Brasileira, 21, 120-122. https://doi.org/10.1590/S1413-78522013000200010

[9] Goldring, M.B. (2000) The Role of the Chondrocyte in Osteoarthritis. Arthritis \& Rheumatology, 43, 1916-1926. https://doi.org/10.1002/1529-0131(200009)43:9<1916::AID-ANR2>3.0.CO;2-I

[10] Kim, H.A., Lee, Y.J., Seong, S.C., Choe, K.W. and Song, Y.W. (2000) Apoptotic Chondrocyte Death in Human Osteoarthritis. The Journal of Rheumatology, 27, 455-462.

[11] McAlindon, T.E., Bannuru, R.R., Sullivan, M.C., Arden, N.K., Berenbaum, F., BiermaZeinstra, S.M., Hawker, G.A., Henrotin, Y., Hunter, D.J., Kawaguchi, H., Kwoh, K., Lohmander, S., Rannou, F., Roos, E.M. and Underwood, M. (2014) OARSI Guidelines for the Non-Surgical Management of Knee Osteoarthritis. Osteoarthritis Cartilage, 22, 363-388. https://doi.org/10.1016/j.joca.2014.01.003

[12] Salvato, K.F., Santos, J.P., Pires-Oliveira, D.A., Costa, V.S., Molari, M., Fernandes, M.T., Poli-Frederico, R.C. and Fernandes, K.B. (2015) Analysis of the Influence of Pharmacotherapy on the Quality of Life of Seniors with Osteoarthritis. Revista Brasileira de Reumatologia, 55, 83-88.https://doi.org/10.1016/j.rbr.2014.08.006

[13] Gibson, M., Li, H., Coburn, J., Moroni, L., Nahas, Z., Bingham $3^{\text {rd }}$, C., Yarema, K. and Elisseeff, J. (2014) Intra-Articular Delivery of Glucosamine for Treatment of Experimental Osteoarthritis Created by a Medial Meniscectomy in a Rat Model. Journal of Orthopaedic Research, 32, 302-309. https://doi.org/10.1002/jor.22445

[14] Rezende, M.U., Hernandez, A.J., Oliveira, C.R. and Bolliger Neto, R. (2015) Experimental Osteoarthritis Model by Means of Medial Meniscectomy in Rats and Effects of Diacerein Administration and Hyaluronic Acid Injection. Sao Paulo Medical Journal, 133, 4-12. https://doi.org/10.1590/1516-3180.2013.6730001

[15] Wang, L., Wu, Y., Tan, Y., Fei, X., Deng, Y., Cao, H., Chen, B., Wang, H., Magdalou, J. and Chen, L. (2014) Cytotoxic Effects of the Quinolone Levofloxacin on Rabbit Meniscus Cells. Journal of Applied Toxicology, 34, 870-877. https://doi.org/10.1002/jat.2903

[16] Goto, K., Yabe, K., Suzuki, T., Takasuna, K., Jindo, T. and Manabe, S. (2008) Gene Expression Profiles in the Articular Cartilage of Juvenile Rats Receiving the Quinolone Antibacterial Agent Ofloxacin. Toxicology, 249, 204-213. https://doi.org/10.1016/j.tox.2008.05.005

[17] Guzman, R.E., Evans, M.G., Bove, S., Morenko, B. and Kilgore, K. (2003) Mono-IodoacetateInduced Histologic Changes in Subchondral Bone and Articular Cartilage of Rat Femorotibial Joints: An Animal Model of Osteoarthritis. Toxicologic Pathology, 31, 619-624.

https://doi.org/10.1080/01926230390241800

[18] van Buul, G.M., Siebelt, M., Leijs, M.J., Bos, P.K., Waarsing, J.H., Kops, N., Weinans, H., Verhaar, J.A., Bernsen, M.R. and van Osch, G.J. (2014) Mesenchymal Stem Cells Reduce Pain but Not Degenerative Changes in a Mono-Iodoacetate Rat Model of Osteoarthritis. Journal of Orthopaedic Research, 32, 1167-1174. https://doi.org/10.1002/jor.22650

[19] Barreto, R.B., Sadigursky, D., de Rezende, M.U. and Hernandez, A.J. (2015) Effect of Hyaluronic Acid on Chondrocyte Apoptosis. Acta Ortopedica Brasileira, 23, 90-93. https://doi.org/10.1590/1413-785220152302144341

[20] Lampropoulou-Adamidou, K., Lelovas, P., Karadimas, E.V., Liakou, C., Triantafillopoulos, I.K., Dontas, I. and Papaioannou, N.A. (2014) Useful Animal Models for the Research of Osteoarthritis. European Journal of Orthopaedic Surgery and Traumatology, 24, 263-271. 
https://doi.org/10.1007/s00590-013-1205-2

[21] Kuyinu, E.L., Narayanan, G., Nair, L.S. and Laurencin, C.T. (2016) Animal Models of Osteoarthritis: Classification, Update, and Measurement of Outcomes. Journal of Orthopaedic Surgery and Research, 11, 19. https://doi.org/10.1186/s13018-016-0346-5

[22] Goto, K., Imaoka, M., Goto, M., Kikuchi, I., Suzuki, T., Jindo, T. and Takasaki, W. (2013) Effect of Body-Weight Loading onto the Articular Cartilage on the Occurrence of Quinolone-Induced Chondrotoxicity in Juvenile Rats. Toxicology Letters, 16, 124-129.

https://doi.org/10.1016/j.toxlet.2012.11.017

\section{Submit or recommend next manuscript to SCIRP and we will provide best service} for you:

Accepting pre-submission inquiries through Email, Facebook, LinkedIn, Twitter, etc. A wide selection of journals (inclusive of 9 subjects, more than 200 journals)

Providing 24-hour high-quality service

User-friendly online submission system

Fair and swift peer-review system

Efficient typesetting and proofreading procedure

Display of the result of downloads and visits, as well as the number of cited articles Maximum dissemination of your research work

Submit your manuscript at: http://papersubmission.scirp.org/

Or contact jbm@scirp.org 